\title{
Cutaneous metastases of lung cancer
}

\author{
Rammurti Kamble, Lalit Kumar, Vinod Kochupillai, Atul Sharma, MS Sandhoo, BK \\ Mohanti
}

\begin{abstract}
Summary
The reported incidence of skin metastases from lung cancer varies from 2.8-7.5\%. In the present study $8.7 \%$ of patients had skin metastases, with head and neck being the most common sites, nodular lesions the most common, and adenocarcinoma the most frequent histology. Although most patients develop these lesions during the course of a known progressive disease, they may be the presenting manifestation of a primary tumour in the lung. The occurrence of skin lesions in lung cancer announces an ominous prognosis. The response to chemotherapy is poor, possibly due to poor blood supply to the skin; monitoring response to chemotherapy, however, is easier when such lesions are present.
\end{abstract}

Keywords: radiation therapy, lung cancer, cutaneous metastases.

The commonest tumour to metastasise to the skin in males is lung cancer with a reported incidence of $2.8-7.5 \%^{1,2}$ Although the anterior trunk, and head and neck regions are reported to be common sites, skin metastases may arise anywhere on the body. ${ }^{3}$

Lung cancer metastasises to almost every organ. Frequent extrathoracic sites include liver, adrenals, bones, brain and kidney. ${ }^{4}$ Skin metastases, though uncommon, can be the sole manifestation of the disease, and could be a sensitive monitor of response to chemotherapy. ${ }^{5}$

Cutaneous metastatic lesions due to lung cancer are physically indistinguishable from those due to carcinoma originating elsewhere in the body. They occur with sufficient frequency and at any site, that lung cancer should always

Institute Rotary

Cancer Hospital, All

India Institute of

Medical Sciences, New

Delhi 110029, India

Department of

Medical Oncology

R Kamble

L Kumar

V Kochupillai

A Sharma

Department of

Radiodiagnosis

MS Sandhoo

Department of

Radiation Therapy

BK Mohanti

Accepted 29 June 1995 be considered in the differential diagnosis of patients with nodular skin lesions. ${ }^{6}$

\section{Materials and methods}

Medical records of 491 patients with lung cancer at the Institute Rotary Cancer Hospital, All India Institute of Medical Sciences, New Delhi, were studied. Of these 43 patients were found to have cutaneous metastases. Their site, duration, histology and response to therapy were assessed. Skin metastases due to primaries other than lung were excluded. Those with subcutaneous metastases involving lymph nodes or direct extension to the skin of the chest wall were excluded from the analysis, as were patients with incomplete medical records. Skin nodules were either biopsied or subjected to fine needle aspiration cytology (FNAC) in all but three patients.

\section{Results}

A total of 43 patients were found to have cutaneous metastases (34 men and nine women). Ages ranged from 30 to 85 years (mean 54.5). All except seven patients were smokers. The distribution of the skin lesions were variable. Scalp, head and neck were the most common sites ( $49 \%$ ), followed by chest $(37 \%)$, lower limb (5\%), and upper limb (2\%). Three patients $(7 \%)$ had metastases to both head/neck and chest/abdomen (box 1). Skin nodules were the most common manifestation (figures 1 and 2); 11 patients had multiple lesions (box 1). Skin ulceration was not common, only one patient having ulceration on the top of the nodule. Black discolouration of skin was noted in three patients. The size of the nodules was $2-10 \mathrm{~cm}$, average $4 \mathrm{~cm}$. The lesions were firm, nodular, mobile, and large enough to be noted by patients themselves.

Skin metastases were the first clinical manifestation of disease in five patients; preceding endobronchial symptoms by $4-6$

\begin{tabular}{|c|c|}
\hline \multicolumn{2}{|l|}{$\begin{array}{l}\text { Characteristics of cutaneous } \\
\text { metastases in } 43 \text { patients }\end{array}$} \\
\hline $\begin{array}{l}\text { Distribution of skin lesion } \\
\text { - scalp, head and neck } \\
\text { - chest, abdomen (trunk) } \\
\text { - scalp, head-neck and chest abdomen } \\
\text { - lower limb } \\
\text { - upper limb }\end{array}$ & $\begin{array}{l}21(49 \%) \\
16(37 \%) \\
3(7 \%) \\
2(5 \%) \\
1(2 \%)\end{array}$ \\
\hline $\begin{array}{l}\text { Description of cutaneous lesions } \\
\text { - number of nodules } \\
\text { - size of nodule } \\
\text { - firm mobile nodule without } 3 \\
\text { overlying skin changes } \\
\text { - firm mobile nodule with } \\
\text { tense and shiny skin } \\
\text { - nodule with black } \\
\text { discolouration of skin } \\
\text { - ulcerated nodule }\end{array}$ & $\begin{array}{c}32(73 \%) \\
11(27 \%) \\
(\text { av } 4 \mathrm{~cm}) \\
31(72 \%) \\
8(19 \%) \\
3(7 \%) \\
1(2 \%)\end{array}$ \\
\hline $\begin{array}{l}\text { Histology } \\
\text { - adenocarcinoma } \\
\text { - squamous cell tumour } \\
\text { - small cell tumour } \\
\text { - uncharacterised lung tumour }\end{array}$ & $\begin{array}{c}18(45 \%) \\
14(30 \%) \\
8(17 \%) \\
3(8 \%)\end{array}$ \\
\hline
\end{tabular}

Box 1 


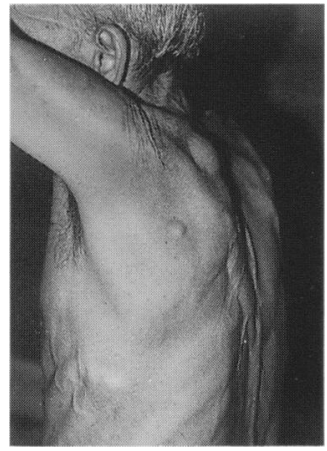

Figure 1 Chest wall nodules, prominent venous dilatation can be seen, due to superior vena cava obstruction

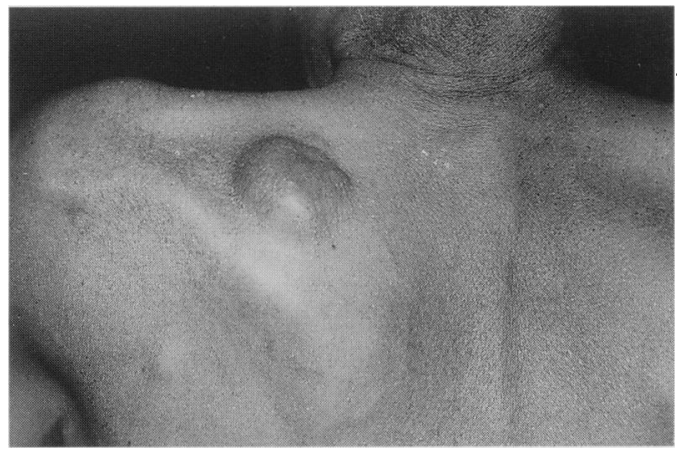

Figure 2 Two firm, mobile, metastatic nodules without skin changes in a patient with small cell carcinoma

months. Adenocarcinoma was the most common histology (box 1). Poorly differentiated tumours $(77 \%)$ had a greater propensity for metastases than well-differentiated tumours $(23 \%)$. Four patients had mucin-secreting adenocarcinoma on FNAC/biopsy of skin lesion. These patients were investigated to rule out gastrointestinal primaries.

Most patients (65\%), had metastases to more than one organ system including liver, bone marrow, adrenals, brain. However 15 patients $(35 \%)$, had no detectable lesion other than skin. Bone marrow metastases were seen in five $(12 \%)$ and cranial metastases in four $(9 \%)$ patients.

Most patients were treated by radiation therapy alone $(42 \%)$, while five patients $(12 \%)$ received both radiation therapy and chemotherapy. Patients on chemotherapy alone $(21 \%)$ did show initial appreciable reduction in the size of cutaneous nodule, but later these lesions progressed. None had complete diappearance of the skin nodule. Chemotherapy consisted of either a combination of cisplatin and VP-16 or cyclophosphamide, adriamycin and vincristine. Radiation therapy of painful skin lesion was given to only one patient. Eleven patients $(25 \%)$ were offered only supportive palliative therapy. The mean survival of these 43 patients following the appearance of the skin nodule was four months. Only two survived for more than one year.

\section{Discussion}

Dermatological manifestations of lung cancer as a part of the paraneoplastic syndrome are seen in less than $1 \%$ of cases. Various neoplastic and paraneoplastic dermatological manifestations are described in box 2 .

Skin metastases of a lung cancer are not uncommon. ${ }^{2,9}$ In males, the commonest tumour to metastasize to the skin is lung cancer. ${ }^{3}$ They usually appear in patients with known lung cancer signifying aggressive tumour behaviour. They are rarely a presenting manifestation of an occult primary pulmonary tumour, ${ }^{6,10}$ but any unexplained fresh skin lesion should be investigated to rule out lung cancer.

\begin{tabular}{|l|}
\hline Dermatological manifestations of \\
lung cancer \\
\hline Paraneoplastic \\
- acanthosis nigricans \\
- pruritis \\
- pigmentation \\
- necrotic migratory erythema ${ }^{7}$ \\
- deriple palm ${ }^{8}$ \\
- migratory thrombophlebiti \\
- acquired icthyosis \\
Neoplastic \\
- direct extension to the chest wall and skin \\
- metastatic - usually a cutaneous nodule \\
without overlying skin changes \\
\hline
\end{tabular}

Box 2

\begin{tabular}{|l|}
\hline Summary points \\
\hline $\begin{array}{l}\text { Cutaneous metastases from lung cancer are } \\
\text { frequent; any fresh skin lesion in a smoker } \\
\text { should lead to suspicion of a primary in the lung, } \\
\text { even in asymptomatic patients }\end{array}$ \\
\hline
\end{tabular}

Box 3

Cutaneous metastases are a sign of an aggressive, poorly differentiated, malignant tumour. Of the various histologies, adenocarcinomas are the most common. ${ }^{5}$ Four patients in the present study had mucin-secreting adenocarcinomas which are known to follow an aggressive course.

The appearance of a skin nodule provides a valuable tool for monitoring response to chemotherapy. ${ }^{5}$ The response, however, may be unrelated to the primary tumour, as skin lesions may be less sensitive to chemotherapy due to the relatively poorer blood supply of the skin. After an initial partial response to chemotherapy all lesions in our study progressed and even in patients with small cell lung cancer, a complete response at the cutaneous metastatic site was not observed.

Lung cancer patients with cutaneous secondaries are not likely to be cured. Such metastases signify a fast-growing aggressive primary in the lung. They aid rapid diagnosis when they are the sole manifestation of an occult primary. These patients have an extremely poor prognosis, despite aggressive combinations of chemotherapy and/or radiation therapy. Generally, therefore, only palliative chemotherapy is offered, with or without radiation. The continuation of palliative treatment needs to be balanced between toxicity and benefits obtained. Radiation therapy to the metastatic skin lesion is not indicated unless associated with severe pain or bleeding, which is not common.

We conclude that scalp, head/neck, and chest are the most common sites for skin metastases in lung cancer. They usually present as a cutaneous nodule and their response to 
chemotherapy is generally poor; due partly to the poor blood supply of the skin. Their recognition, however, is important; every fresh cutaneous lesions should lead to suspicion of a bronchogenic carcinoma, particularly if the

1 Ringold IM. Cutaneous metastases from internal carcinoma Cancer 1966; 19: 162-8.

Rosen T. Cutaneous metastases. Med Clin North Am 1980 64: 885-900.

3 Brownstein M, Helwig E. Pattern of cutaneous metastases. Arch Dermatol 1972; 105: 862-8.

4 Swelden K, Degreef H, Sciot R, Van Damme B, Peeters C. Lung cancer with skin metastases. Dermatology 1992; 185: 305-6.

5 Dreizen $S$, Dhingra $H$, Chiuten DF, Umawasdt $T$, Valdivieso $M$. Cutaneous and subcutaneous metastases of lung cancer. Postgrad Med 1986; 80: 111-6.

6 Cancer. Postgrad Med 1986; 80: 111-6. 1990; 97: 757-9. patient is a smoker. All such lesions should be biopsied. We also conclude that a cutaneous metastases is the most common dermatological manifestation of lung cancer.

7 Hunstein W, Trimper LH, Dummer R, Schwechheimer K. Glucagonoma syndrome and bronchial carcinoma. Ann Intern Med 1988; 109: 920.

8 Cohen PR, Grossman MC, Almeida L, Kurzrock R. Tripe palm and malignancy. $\mathcal{f}$ Clin Oncol 1989; 7: 669.

9 Surinach-Caralt JM, Alegre-Martin J. Cutaneous metastases - a rare finding? (editorial) Ann Med Interna 1993; 10: 534.

10 Brownstein MH, Helwing EB. Metastatic tumors of the skin. Cancer 1972; 29: 1298-307.

\section{European Medical Research Group}

\section{EUROPEAN DOCTORS IN LONDON}

\section{Fellowship of \\ Postgraduate Medicine}

The European Medical Research Group has been formed by the European Association of Internal Medicine with the support of the Fellowship of Postgraduate Medicine, to provide a meeting place for professional and social contact among physicians in training, particularly those from continental Europe. Regular meetings are held at the Medical Society of London. An invited lecture is given, preceded by poster presentations and followed by a buffet supper.

Members of the group receive regular mailings about the meetings.

Next meeting: Tuesday 5 December 1995

Speaker: Dr Graham R V Hughes on 'The Antiphospholipid Syndrome'

European research fellows and other doctors who would like details of these meeting should write to:

Dr D R J Singer, c/o The Fellowship of Postgraduate Medicine, 12 Chandos Street, London W1M 9DE, UK. Tel 0171636 6334; fax 01714362535 